\title{
The utilization of unmanned aerial vehicles in combating illegal bunkering activities in the Niger Delta regions of Nigeria
}

\author{
Kayode Sunday John, Dada ${ }^{*} \cdot$ Jechoniah, Akila $^{* *}$
}

\begin{abstract}
In contemporary surveillance and reconnaissance efforts, unmanned aerial vehicles (UAVs) have been widely deployed in dangerous, low-altitude regions where manned aircrafts cannot navigate easily because of their size, purchasing costs for environmental remote sensing, monitoring, and combat mission for military operations. As UAVs are used in compromising situations, they are designed to be low cost in the event of failed recovery process and there is increased operational flexibility for military applications and non-military development. This paper provides an overview of the use of UAVs in combating illegal bunkering activities. It classifies these vehicles based on performance and size. The paper seeks to proffer potential solutions for its adoption in the Niger Delta for forestalling security, monitoring and surveillance of multinational oil companies' pipelines operating in the region, tactical responses by security agencies to address emergency situations of
\end{abstract}

(a) (1) This work is licensed under a Creative Commons Attribution 4.0 International License.

* (First Author) Department of Library and Information Science, Ahmadu Bello University, Zaria, Kaduna State, Nigeria, kayodescholar@gmail.com

** (Corresponding Author) Physical Training, Depot Nigerian Army, Zaria, Kaduna State, Nigeria, Jechoniahakila@gmail.com 
oil spillage, and illegal bunkering activities for the promotion of the nation's economic development.

Keywords : unmanned aerial vehicle, bunkering, combat, Niger Delta, deployment 
The utilization of unmanned aerial vehicles in... / Dada Kayode Sunday, John • Jechoniah, Akila 103

\section{I . Introduction}

Environmental remote sensing and monitoring are primarily concerned with the collection and interpretation of data on oceans, land, and atmosphere from a remote vantage point. Remotely sensed data have been successfully used to predict the weather and track hurricanes, observe coastal dynamics and detect pollutants, secure pipelines, and map coastal land cover including tidal wetlands, forests, agriculture, and urban areas (Jensen, 2007). According to Klemas (2015), remotely sensed and monitored data from coastal and environmental zones is collected from the oceans, land, and atmosphere and interpreted with a view to successfully to predict the weather, track hurricanes; observe coastal dynamics, secure pipelines, coastal land cover mapping, and detect pollutants (Jensen, 2007). This has been made possible with the use of aircrafts; however, manned aircraft overflights can be expensive (Klemas, 2011). With the use and adoption of unmanned aerial platforms, the cost is dramatically reduced. GPS-guided unmanned aerial vehicles (UAVs) have the capacity to obtain very high spatial resolution $(10 \mathrm{~cm})$ imagery of specific landscape features with revisit times determined by the operator, as opposed to fixed satellite revisit times (Lechner, Fletcher, Johansen, \& Erskine, 2012). As a result, UAVs like drones and quadcopters, are now being used effectively in many environmental studies, and monitoring, military, and reconnaissance operations (Crouch, 2005).

\section{Background of the Study}

Nigeria is the largest producer of crude oil (Premium Motor Spirit) in Africa and the eighth largest producer in the world. The petroleum industry accounts for $90 \%$ of Nigeria's total foreign exchange revenue.

\section{The Niger Delta}

The Niger Delta comprises 9 states that share borders with each other. The population of the area is over 45 million (45,000,000), includes about 40 ethnic groups that speak over 250 dialects, and is spread across 5,000 communities in the region. The Niger Delta, as indicated officially by the Nigerian Government, stretches across around 70,000 $\mathrm{km}^{2}(27,000 \mathrm{sq} \mathrm{mi})$ and constitutes 7.5\% of Nigeria's territorial mass. It includes present-day Bayelsa, Delta, and Rivers States within its territory (Bodo \& Gimah, 2020). The Niger Delta region is blessed with abundant physical and human resources, good agricultural land for cultivation, extensive forests, and most of the nation's oil and gas deposits, which are explored on a daily basis for the economic 
development of the country. The region is the main oil producing area in Nigeria. It accounts for $98 \%$ and produces two million barrels of crude oil per day. This has made it the main revenue-generating region in the country and the backbone of the nation's economy; however, as a result of illegal bunkering in the delta region that has resulted in vandalization and crude oil theft, Nigeria has lost USD 11 billion (Hope for Niger Delta Campaign, 2013; Idachaba, 2013).

Despite the exploration of oil in the region, the World Bank (1995) noted that citizens in the region live on less than USD 1 per day as a measure of absolute poverty and declared it a least developed region, with a per capita income of under USD 280 (Hope for Niger Delta Campaign, 2013). With the region threatened by deteriorating and harsh economic conditions, there were environmental oil degradation (not safe for farming and fishing), and poor infrastructural development, which are not been adequately addressed by the present government's policies and actions in the promotion of sustainable development in the region (Wifa, 2008). This region is plagued with widespread acts of vandalism as a result of illegal bunkering, breakage, and corruption, which, in turn, has affected the development of the region and Nigeria as a whole (Davis, Von Kemedi, \& Drennan, 2006). This has triggered turmoil among the youth in the region, who seek greener pastures and possession of basic social amenities by engaging in vandalism and bunkering the oil exploration companies' pipelines to meet their needs.

Although measures by the Nigerian Government and Shell Petroleum Development Company of Nigeria (SPDC) for compensation and strategies for providing better living conditions in order to curb illegal bunkering activities, a 2015 report indicated that SPDC compensated the people of Bodo after a filled a case in the United Kingdom, where Shell is incorporated. Shell accepted responsibility for the oil spills in Bodo in 2008 and 2009. It paid USD 83.4 million, 82\% short of their original demand of USD 454.9 million to the people of Bodo in Ogoniland (Bodo \& Gimah, 2019). It was later reported that from this settlement, every resident who was aged 18 years and above received a sum of N600,000 as their share of the compensation from SPDC (Bodo \& Gimah, 2019). Other communities in Ogoniland like Goi, Mogho, and K-Dere were left out of the settlement from SPDC for the oil spills on their land and the destruction of their livelihood, even though they were also affected by the oil spills as a result of operational failure, and not the ones orchestrated by oil bunkers. This singular reason has left other regions and the drive for the government to resolve such incidences has led to little impact due to inadequate knowledge of the scale of its occurrence, patterns and not hitting the nail on the head, efforts such as provision of scholarships to community children, gainful employment, social basic amenities for the survival of the region and the country at large (Bodo \& Gimah, 2019). 
The utilization of unmanned aerial vehicles in... / Dada Kayode Sunday, John • Jechoniah, Akila 105

To achieve these objectives, this paper investigates the various ways in which illegal bunkering is performed and makes the case for the deployment of UAV systems as a potential solution. It also highlights the role of the Nigerian Government and major oil industry players and other stakeholders in addressing the geo-economic challenges in Nigerian society to foster development in all sectors of the Nigerian economy.

\section{П. Concept of illegal bunkering}

Illegal bunkering includes the practices of oil exploration and exportation without proper approval of the constituted authority, as a result of theft for personal and commercial purposes. Illegal bunkering of oil in the Niger Delta is widespread and conducted in a surprisingly open manner. It is common in places like Port Harcourt, Warri, Okrika, Bonny, Akassa, and Soku. This region has major loading points for the exportation of oil into the international market. Other key sites include Jones Creek and Cawthorne Channel. The studies of Kemedi (2006) indicated that 140,000 barrels of crude oil is carted away by illegal bunkers as a result of their activities, this act has possessed a significant loss of USD 11 billion of the nation's foreign exchange due to oil theft and vandalism of pipelines by bunker. The amount gave rise in 2001 to 724,171 barrels per day. The average daily figure from January to October 2002 was 699,763 barrels. This trend was addressed by the implementation of the Peace and Security Strategy, and a host of declarations, charters, agendas, and resolutions that were addressed to oil exploration companies (Bodo, Gimah, \& Seomoni, 2020; Campbell, 2015).

Illegal oil bunkering has made oil spillages and explosions a common occurrence in the Niger Delta region (Campbell, 2015). The phenomenon is rather common in the region as most people live in abject poverty, and have bad roads and poor healthcare facilities, and suffer from the rise of water-borne diseases that are prominent in the area as a result of oil spillage into drinking water. Nigeria's state oil company and its joint venture partners have spent USD 360 million on cleaning up the Niger Delta over the past two years (Bodo \& Gimah, 2020). SPDC claimed that 70 percent of all oil spills over the past 5 years was the after effect of a sabotage on their facilities (Bodo, Gimah, \& Seomoni, 2020; Campbell, 2015).

\section{Illegal bunkering in the Niger Delta}

Illegal bunkering is carried out in the Niger Delta at different methods, levels and quantities with various methods. The most popular method for stealing crude oil is to puncture the pipeline 
conveying the product from one point to another or to tap it at the point where it has been punctured for business and exchange purposes (Adedoyin, 2016; Adishi, \& Hunga, 2017). According to previous studies of (Adishi \& Hunga, 2017; Asuni, 2009; Katsouris \& Sayne, 2013), mode of illegal bunkering and oil theft is viewed in the following ways as listed below:

a. The small-scale oil theft for resale in the local market.

b. Direct tapping into pipelines joints with a horsehead from the wellhead through the practical removal of the Christmas tree and joints.

c. Unlicensed and forged bills of lading for resale of excess lifting of crude oil.

d. The destruction of company pipeline with explosives for disruption of oil supply to loading stations.

First, mostly conducted by community dwellers who hide under the guise of violence in the Niger Delta region, to cause havoc, the second category brings in more technical sophisticated equipments to extract the crude for resale of the stolen product in barges into the seas shore for transportation into vessels in exchange of currency and weapons used to fuel violence. While the third ways are a result of misappropriation and corruption of officials who are charged with the responsibility of licensing buyers, resale the products through the black market with forged bills of lading for personal gains (Boris, 2015, p. 565). Lastly, is a combination of category one and two with political influence (Adishi \& Hunga, 2017). The last category causes most of the oil spills and environmental degradation and pollution as blasting and bombing of the oil installations and pipelines is aimed at halting the production and supply of crude oil in retaliation for the neglect by major oil industry stakeholders and the government in addressing societal needs.

\section{UAVs}

UAVs are powered aircrafts that are remotely or autonomously operated with pre-programmed flight planning. The two main types of UAV configurations are fixed (airplane) and rotary (helicopter) wings (Klemas, 2015).

US Office of the Secretary of Defense (2013), a UAV is a "system whose components include the necessary equipment, network, and personnel to control an unmanned aircraft." UAVs are also known as drones. They offer increased operational process, versatility, and high-resolution 
The utilization of unmanned aerial vehicles in... / Dada Kayode Sunday, John • Jechoniah, Akila 107

imaging data at low costs for conventional platforms. In this sense, the ability of UAVs to capture imagery concurrent with field observations solves a common remote-sensing problem in the acquisition of ground and remote-sensing data for problem-solving approach and research (Klemas, 2015). Military applications of UAV technology have been steadily transferred to civilian and research applications. Improvements in the design of flight control systems have transformed these platforms into research-grade tools that are capable of acquiring high-quality images and geophysical/biological measurements (Hugenholtz, Moorman, Riddell, \& Whitehead, 2012).

\section{Classification of UAVs}

The small unmanned aerial vehicles class (also sometimes called Mini-UAV) applies to UAVs that have at least one dimension that is greater than $50 \mathrm{~cm}$, at 55 pounds, and no larger than 2 meters (Federal Aviation Administation: FAA, 2007; Kody \& Bramesfeld, 2012). According to Austin (2011), Mini UAVs usually have a mass that is under $20 \mathrm{~kg}$, but not as small as the Micro Air Vehicles (MAVs), which can be hand-launched and operate at ranges of up to about $30 \mathrm{~km}$. Over the years, various scholars have continued to use similar vague definitions of Mini UAVs. This has resulted in the absence of a common identity for Mini UAVs across the scientific world and among manufacturers (Ramesh \& Jeyan, 2020). Consequently, there is no uniformity in the definitions of Mini UAVs. However, each is classified based on particular parameters. Cai, Dias, and Seneviratne (2014) referred to Mini UAVs as miniatures and clubbed them with aerial vehicles (MAVs) with a wingspan or rotorspan of under $15 \mathrm{~cm}$. Instead of MTOW, payload attributed with few tens of kilograms has been used to describe a Mini-UAV.

\section{Micro-UAVs (MAVs)}

Micro-UAVs (MAVs) are designed for short mission and surveillance objectives without unobtrusive observation capabilities in hostile environments for military and reconnaissance operations (Watts, Ambrosia, \& Hinkley, 2012).

In military applications. Since the development of MAV, the US Department of Defense in collaboration with industry have developed and deployed MAV Lockheed Sanders "MicroSTAR", and "Black Widow for short mission and surveillance (Watts, Ambrosia, \& Hinkley, 2012). Similarly, MacCreay Works Advances Solutions developed "Nano Hummingbird" an extremely small, low-altitude, short-duration system designed with bird characteristics (weights 19g and a wingspan of $16 \mathrm{~cm}$ ) can hover vertical, horizontal, backward and forward 
directions, equipped real imaging small video camera, with flight endurance of $\sim 8$ minutes or more for surveillance operations (AeroVironment, 2021).

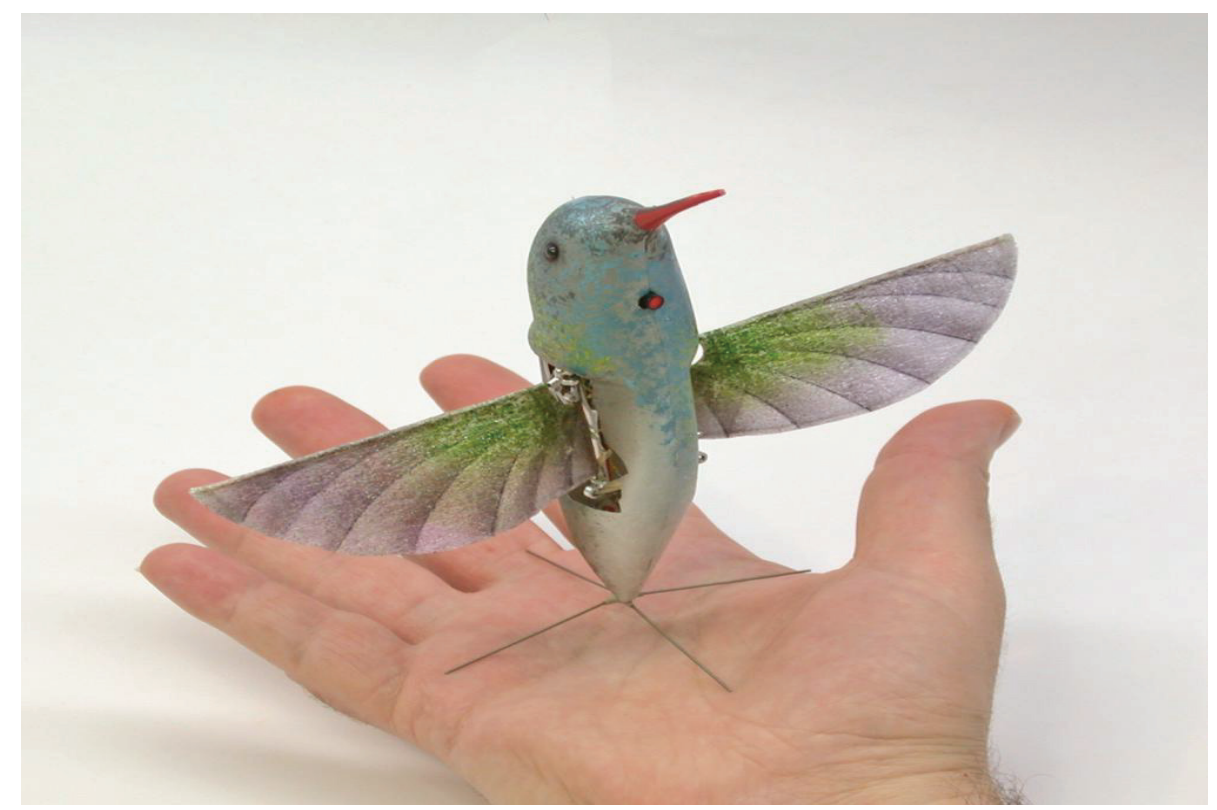

<Figure 1> Nano Handheld MAV

Source: AeroVironment, Inc. 2021 (http://www.avinc.com).

Examples of members of this small UAV class are:

i. The 1 meter long RQ-11 Raven, by US Aero Vironment with a wingspan of $1.4 \mathrm{~m}$; the Turkish Bayraktar (Figure 1), which weighs about $5 \mathrm{~kg}$ and has a data link range of 20 $\mathrm{km}$;

ii. The US Army RQ-7 Shadow (Figure 3);

iii. iFly UAV: It is equippred for fast and accurate parametric studies by researchers to collect data in the study field. 
Some of the UAVs in this class with a rotary-wing design

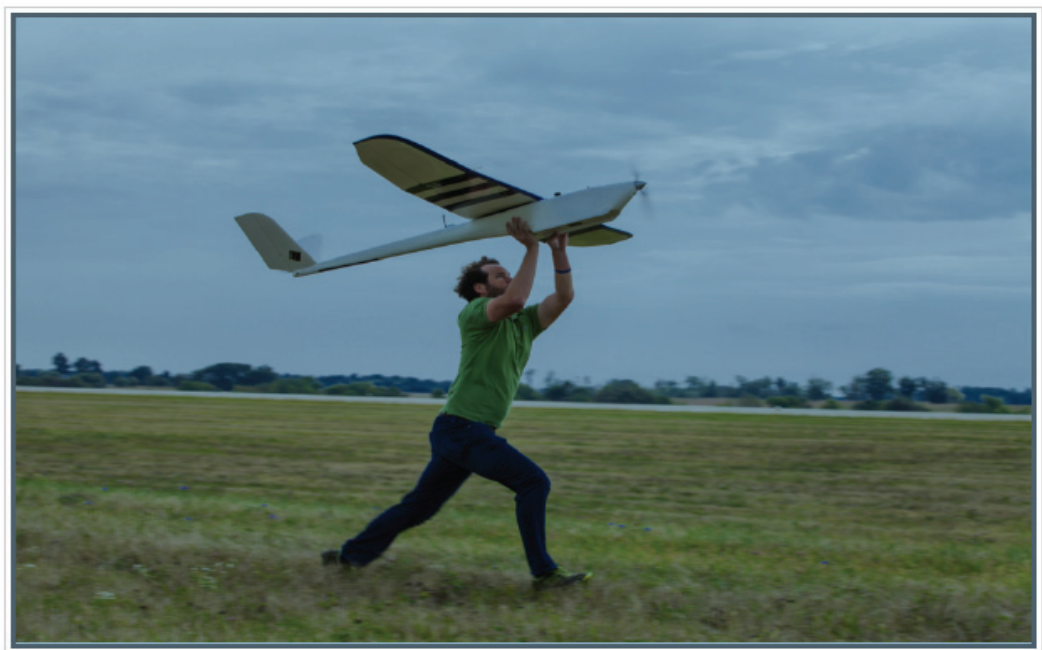

$<$ Figure 2> Hand-launched small UAV

Source: Woolpert (2021). Unmanned Aircraft system (https://woolpert.com/services/uas/)
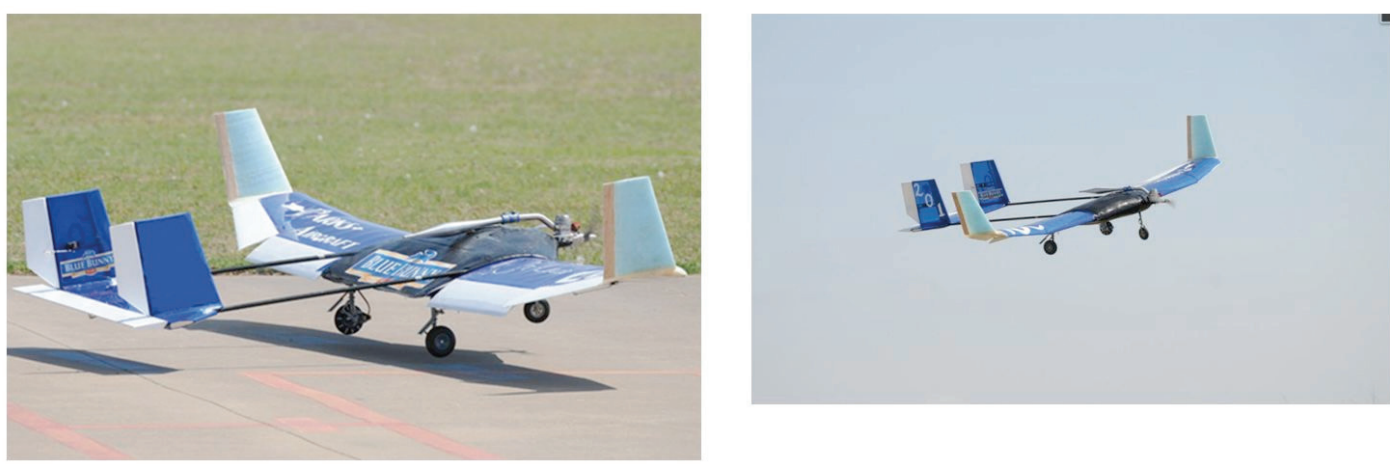

<Figure 3> Saint Louis University's 2011 SAE Aero Design Advanced Class Aircraft

Source: Small UAV Design Using an Integrated Design Tool (Kody \& Bramesfeld, 2012).

\section{Medium UAVs}

The medium UAV classification is based on its light weight which could be carried by one person and smaller than a light aircraft to launch. This class of UAVs characteristics possess a wingspan of about $5-10 \mathrm{~m}$ with a payload of 100 to $200 \mathrm{~kg}$ in size. A classical example of medium fixed-wing UAVs is US Boeing Eagle Eye, the BAE systems Skyeye R4E, the RQ-2 Pioneer, RQ-5A Hunter and the UK Watchkeeper as shown in Figure 4. 


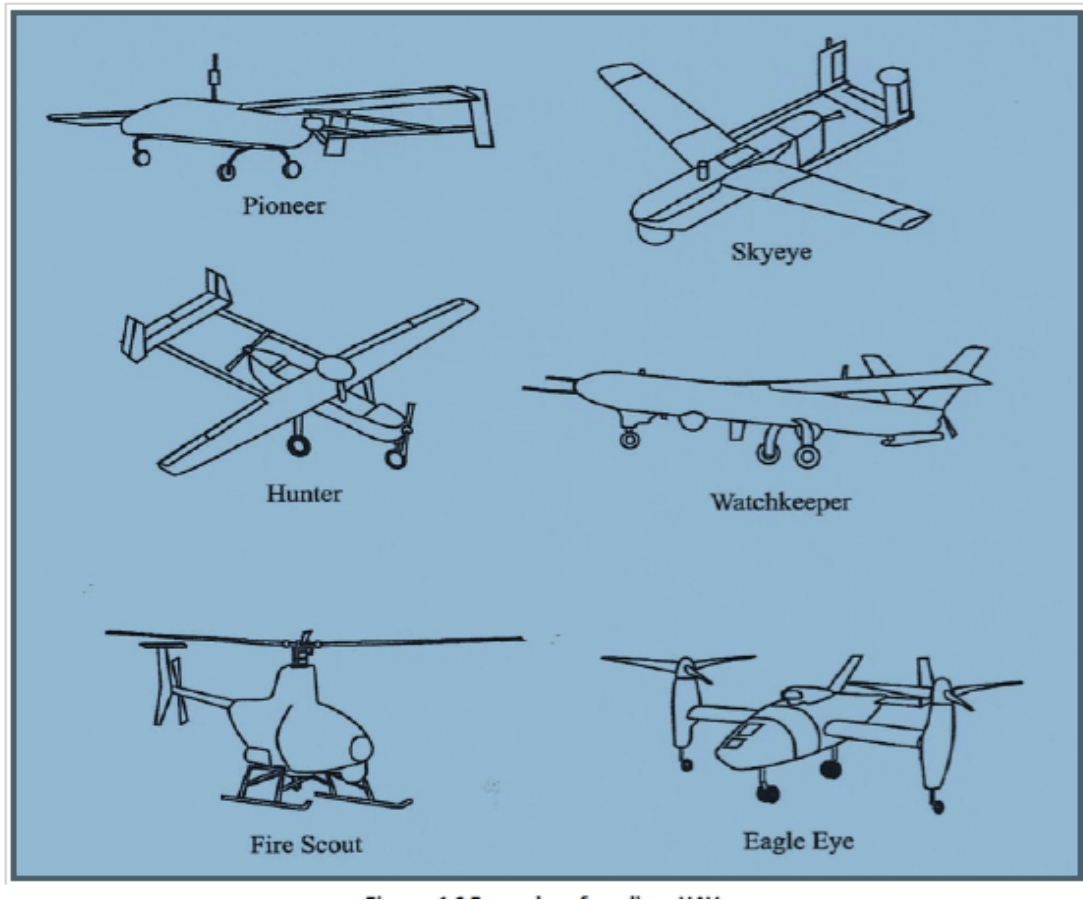

$<$ Figure 4> Examples of medium UAVs

Source: Fahlstrom and Gleason (2012).

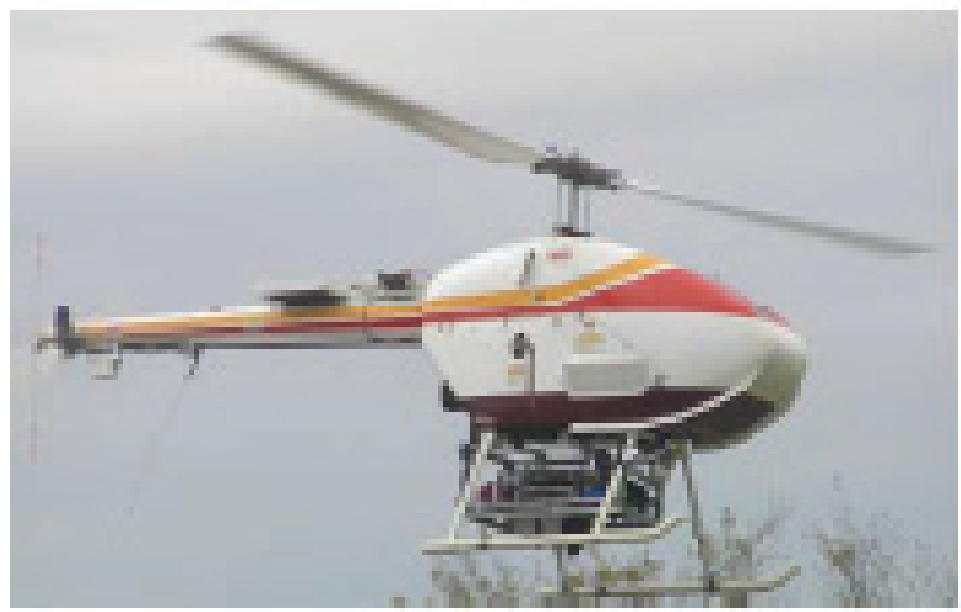

<Figure 5> RPH2 UAV

Source: Ahmed, Nagai, Tianen, and Shibasaki (2008). 
The RPH2, UAV is developed by Fuji Heavy Industries Ltd. with $1.3 \mathrm{~m}$ wide, $4.1 \mathrm{~m}$ long, and $0.8 \mathrm{~m}$ high as shown in Figure 5. It was developed for monitoring missions, detect, search and rescue operations in a disaster area. It has components of high-speed data viewer systems and high-resolution images that help it carry out different responsibilities like extraction of useful data, data quality checking and integration, image viewing, and object detection due to its hovering on low altitude (Ahmed et al., 2008).

\section{ROTARY-WING UAVs}

The advantages of helicopters in military and search/rescue operations are well known. They have proven efficient in many environmental projects including wetland mapping, LIDAR bathymetry, flood/earthquake damage assessment, and oil slick tracking, urban studies (Klemas, 2015). One of the advantages of the Helicopters over fixed-wing aircrafts is that they can hover over a target site for data capturing and inspection, mapping, and spatial readings. Similarly, it was used to rescue inhabitants of New Orleans after Hurricane Katrina made landfall and to conduct damage assessment of the city to inform future planning (Klemas, 2009; NOAA, 2008). It could also be deployed to estimate oil slick, tracking and the movement of spilled oil (Klemas, 2010; Pike, 2014).



<Figure 6> DJI Phantom 2 Vision Quadcopter with integrated camera Source: Amazon (2014). 
Unmanned quadcopters are designed and made with many different configurations. Quadcopters are propelled by identical fixed-pitch four propellers and rotors for clockwise and counter clockwise rotations with its torque load and thrust/lift for stability, tens of long hovering duration, maneuvers, reliability, maintenance, damage control in case of crash (Klemas, 2015; Wikipedia, 2014). An example is shown in Figure 6 a Phantom quadcopter with a purchasing cost of USD 800 integrated with titling 14-MP camera (1080p High Definition video recording), live first-person view (FPV), Wi-Fi streaming of video (330m away, hover for 25 minutes on a single charge, lithium polymer battery, and its telemetry vision application (application) is installed on mobile applications devices for controlling the quadcopter (Klemas, 2015).

\section{Large UAVs}

The large UAV class applies to large UAVs that are mainly used for combat operations by the military. Examples of these include the US General Atomics Predator A and B and the US Northrop Grumman Global Hawk (Figure 7).



Predator A

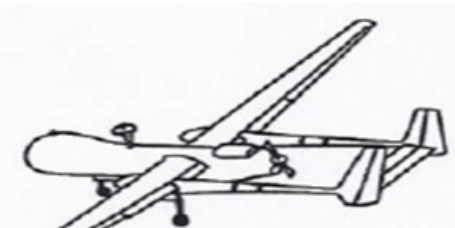

Harfang

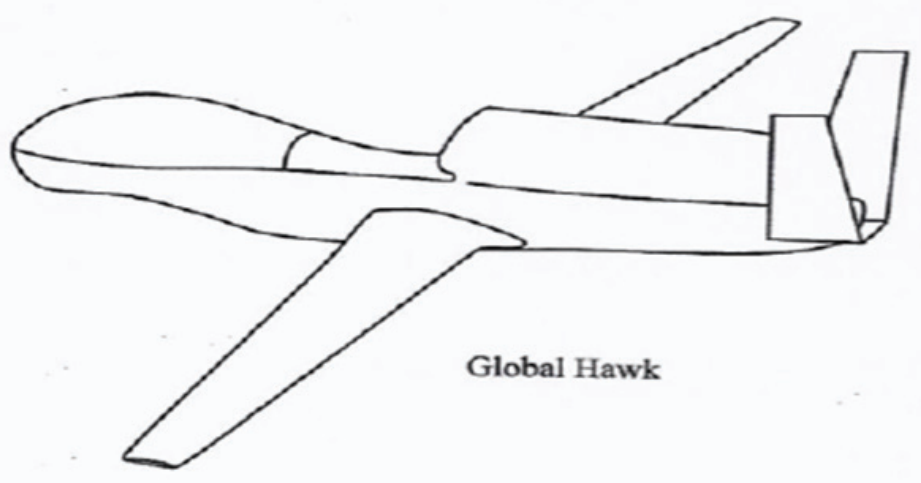

$<$ Figure $7>$ Examples of large UAVs

Source: Fahlstrom and Gleason (2012). 
The Global Hawk is designed by National Aeronautics and Space Administration (NASA) with a long light endurance of over $550 \mathrm{~km} / \mathrm{h}$, and payload of $750 \mathrm{~kg}$ for a range of over $17,000 \mathrm{~km}$ for research operations, and air field missions (NASA, 2009).



<Figure 8> The NASA/NOAA Global Hawk HALE UAS

Source: NASA (2009); Watts, Ambrosia, and Hinkley (2012).

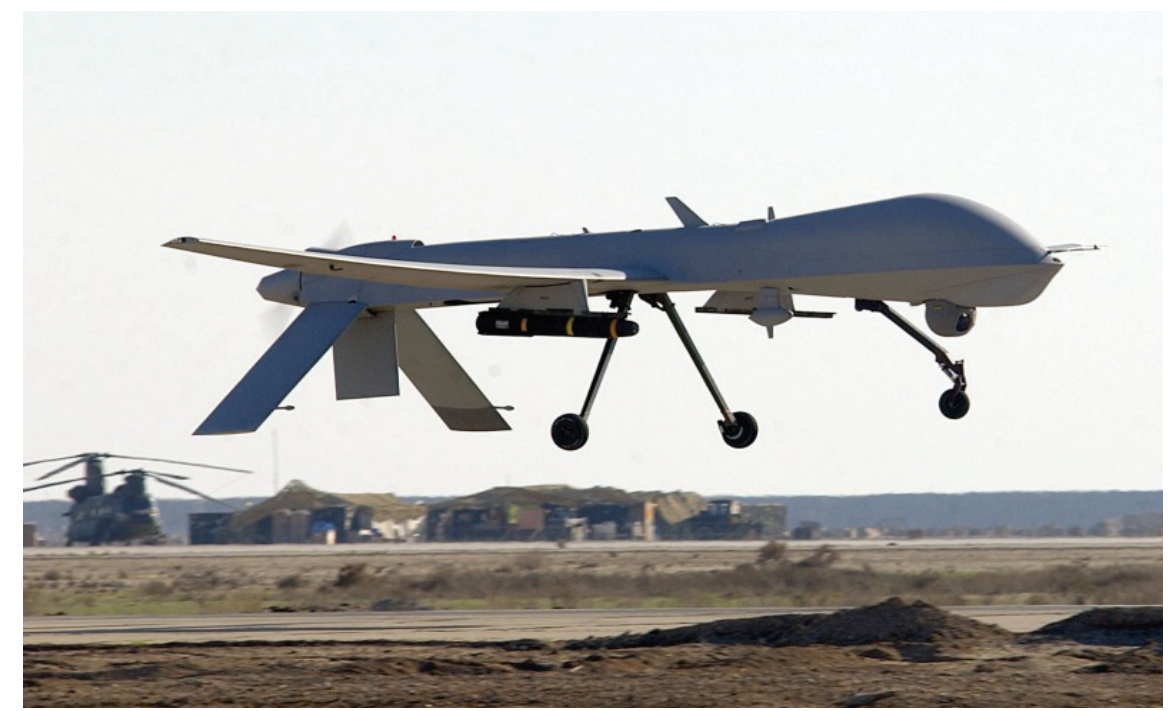

<Figure 9> MQ-1 / MQ-9 PREDATOR

Source: Crouch (2005). 
The MQ-1 Predator (Figure 9) is a General Atomics Aeronautical Systems, Inc., aircraft used for airborne surveillance, target acquisition and armed reconnaissance missions. Its unit is equipped with four aircraft sensors, daylight and night Electro-optic (EO) camera, C-Band line-of-sight data links, Ground-Control Station (GCS), and a Trojan Spirit II Satellite Communications (SATCOM) system for data acquisitions and dissemination during missions (Crouch, 2005).



$<$ Figure 10> RQ-7 SHADOW

Source: Crouch (2005).

The RQ-7 Shadow (Figure 10), a tactical, low-endurance UAV, as compared to mannered costing USD 6.2 million to USD 325,000 to acquire was designed with 68 NM (4-hour endurance), 11.2 feet, 12.8 feet wingspan to conduct reconnaissance, surveillance, brigade-level and target acquisition operations for payloads (Electro-optical (EO)/Infrared camera and communications equipment of 60-pound) (Olive-Drab, 2009). These type of UAV is launched via rail and usually recovered by arresting gear at the ground base station after missions. It has been deployed in Iraq to support intelligence-gathering requirements for US Army and Marine Corps (Crouch, 2005; Olive-Drab, 2009).

\section{Classification According to Range and Endurance}

UAVs are classified base on its size, endurance, and cost. Traditionally, they have been complex systems since its development and deployment that require a wide array of professional ground base staff for its operation from mission control, launching, deployment and 
redeployment for tasks, missions and operations.

\section{Very low-cost, close range UAVs}

This class includes UAVs that have a range of $5 \mathrm{~km}$, endurance time of 20 to 45 minutes, and cost of about USD 10,000 (2012 estimate). Examples of UAVs in this class are the Raven and Draganfly. UAVs in this class are very close to model airplanes (Abdullah, 2020). The Draganflyer X6 (Figure 11) possess a 1kg tri-rotor in flying in altitudes of 2,400m in flights of up to 20 minute-flight durations for missions. It can be used for movement of military equipment's and transport operation in hostile and remote environments not accessible by mannered aircraft and army personnel's.



<Figure 11> Draganflyer X6 VTOL UAS

Source: Watts, Ambrosia, and Hinkley (2012).

\section{Close range UAVs}

This class includes UAVs that have a range of 50km and endurance time of 1 to 6 hours. They are usually used for reconnaissance and surveillance tasks (Abdullah, 2020).

\section{Short range UAVs}

This class includes UAVs that have a range of $150 \mathrm{~km}$ or longer and endurance times of 8 to 12 hours. Like the close range UAVs, they are mainly utilized for reconnaissance and surveillance tasks (Abdullah, 2020). 


\section{Mid-range UAVs}

The mid-range class includes UAVs that have super high speed and a working radius of $650 \mathrm{~km}$. They are used for reconnaissance and surveillance tasks in addition to gathering meteorological data (Abdullah, 2020).

\section{UAV COMPONENTS}

A UAV system comprises a vehicle, a ground-control base station, a tracking control station, and a data dissemination system. The diversity of missions and equipment in different types of UAVs has led to the development of specific control systems to support individual systems (Crouch, 2005). A base station is usually maintained within the domicile of the regions chaired, under the supervision of mission commanders who are given the topography, plans, and missions to execute. The base station is given routes where pipelines are mounted and this region is supervised round the clock as new models of UAVs can loiter around a particular region for over 82 hours (Thomas, 2006). An air operator is given proper training on the supervision of pipeline routes, and imagery in high definition/infrared night vision to study such regions and reports are given to the mission commander and the troops so that they can address illegal bunkering in the region (Thomas, 2006).

The vehicle is equipped with subsystems for payload, propulsion source, avionics equipment, power supply, data link equipment and power supply. Larger UAVs use fuel-powered engines for longer duration of flight and endurances. While, smaller UAVs use gasoline or electrically powered engines. Its payload is usually equipped with Electro-Optical (EO) and Infrared (IR) cameras, signals collection packages, and arrays of equipment for task and missions. The avionics equipment coordinates the direction altitude of flight and speed. The Global Positioning System (GPS) is a critical component of the INS/GPS integration, as it allows small UAVs to navigate with speed and (Procerus, 2006). The data link is also one of the most critical part of the system, as it controls and download data from UAVs to the ground based control station. It is worth noting that, UAVs are pre-installed and programmed with return to base station software in case of loss of communication link with the base station. With its unending and paramount importance of UAVs for provisioning of real-time and near-real-time data (Crooch, 2005; Jaysen \& Yochim, 1998). 


\section{Relevance for the implementation and adoption of UAVs in the Niger Delta region}

The relevance for implementation and adoption is of paramount importance due its various advantages for aerial monitoring for combat missions by homeland security and security agencies. Civilian usage and multinational companies like Shell Nigeria, Total Oil Exploration, LNG Gas could adopt the use of UAVs in mineral resource exploration, oil fields detectations, pipelines monitoring, and search and rescue operations in disaster area in case of emergencies. The current approach for the adoption of this technology is the use of manned vehicles for surveillance that is a price burden in terms of purchase and maintainance for the companies and industry operators in the oil and gas sector in developing country. The Niger Delta region is surrounded by water bodies, with creeks and lagoons used for oil exploration. Thus, the Nigerian Air Force can utilize UAVs to monitor these regions and combat the illegal bunkering of pipelines with regions that are not accessible by aircraft because of humidity and closeness to water (Davis, 2010; Holland et al., 2001).

UAV technology has proven very useful in military reconnaissance on the battlefield such as in Iraq, Afghanistan, and other hostile environments that are not accessible by land. The same capabilities of unmanned systems used in warfare can contribute toward a multitude of civilian applications in the coming years, if it is fully adopted and managed with professional support (Christiansen, 2004; Cummings, da Silva, \& Scott, 2007; Edwards, 2009; Pike, 2003). UAVs can serve as an eye in the sky for oil exploration companies that are located in the region by providing round the clock security information on their pipelines, especially for use in emergency situations like illegal bunkering and vandalized pipelines, and in monitoring activities in their region (Idachaba, 2013; US Joint Forces Command 2009b). UAVs have a number of advantages over manned aircrafts. First, they can stay airborne for long durations and do not require life support systems as do manned aircrafts; thus, UAVs minimize the loss of life on missions that have minimal chances of survival (United States Air Force: USAF, 2009). Another capability found in UAV system is the revolution of remote sensing, natural-resources management and administration since the advent of Geographic Information System (GIS) years back ago. The utility of UAVs in fire mapping applications, for example, has been highlighted in a number of demonstrations of aircrafts of varying size and capabilities (Ambrosia et al., 2011; Watts, Ambrosia, \& Hinkley, 2012).

However, manned vehicles are typically large and expensive (Ahmed et al., 2008). Hazardous environments and operator fatigue can potentially threaten the lives of pilots (Ahmed et al., 2008; Armada International, 2009). UAVs increase the extent of information available for 
military commanders at the strategic, operational, and real-time intelligence, and tactical level operations, which could be used to engage the illegal bunkers and further provide real time information at the tactical level in combating illegal bunkering activities in the region.

\section{Limitation of UAV use}

In a developing country like Nigeria, UAVs can support the continuous surveillance of waterways. This task of surveillance cannot be easily use by stationary units or mannered aircrafts because of the long durations of surveillance, viewing obstructions and area coverage of their GPS bandwidth from the ground base station and the hovering UAVs. UAVs also have some disadvantages when compared to manned aircrafts. They are not autonomous and their control is contingent. When there is loss of communication between the ground operators and the Airborne Air vehicle, it could lead to loss of aircraft.

UAVs are less expensive to acquire, service, maintain, and operate than most manned aircrafts due its cost of purchase. They help collect vital intelligence data, a feat that is dangerous for a manned aircraft to achieve. Limitations in the form of heavy Wind, sand dunes, tornadoes, hurricane, frost, rain, hazy weather, insurgents aerial network hacking, and other environmental factors could hamper their performance for missions and operations. The adoption of UAVs requires funding which is one of the most essential aspect for the procurement of unmannered aerial vehicles, personnel's training, air operators, communication installation, usage, maintenance and development of ground-based stations. And lastly, Defence Academy in Nigeria along with air force training institute could promote the design and development of homemade air vehicle with support from military headquarters, aviation industry for air vehicle project could be challenging, reason being that there are no sensitization and orientation programmes on the advantages of unmannered aerial vehicle in the country.

\section{Conclusion and Future Recommendations}

With the advent and introduction of UAVs into the space, it is necessary for the ability to perform tasks categorized as dull, dirty, and dangerous battle missions. UAVs re-designated as UAS are now being developed to provide cost-effective and efficient solutions for specific applications for both military and civilian use toward environmental surveillance, disaster monitoring, and rescue missions. With its proven capabilities, UAVs will continue to be used 
The utilization of unmanned aerial vehicles in... / Dada Kayode Sunday, John • Jechoniah, Akila 119

extensively in the foreseeable future in both military and civilian applications. Therefore, our study recommends that multinational oil companies in Nigeria (Shell, Total, LNG) and Nigerian National Petroleum Company (NNPC) could adopt the use of UAVs system in collaboration with the military and security agencies by deploying UAV system in checking oil spillage during oil exploration, supervision and monitoring of oil wells in preventing environmental water pollution, land degradation and finding possible solutions to it at its emergence and surveillance of pipelines laid across the region from pipeline vandalism, oil theft and illegal oil bunkering in bringing in a stable Nigerian economy.

Second, the government can ensure that the basic social amenities of the people are met at the grassroot level by making sure that adequate supervision is conducted by using a percentage of oil revenue toward the construction of better road networks, providing youth better business opportunities, establishing good water systems, and offering compensation to degraded farmland owners owing to oil spillage and proper sensitization programs for skills acquisition for the community. This will reduce the influx of youth into illegal bunkering. A good satellite link communication must be kept in place by the companies to keep both digital and analog communications active in supervision, monitoring, surveillance, and reconnaissance. As the operators should be taught basic on how to address emergencies as a result of loss of communication. Nigeria is blessed with vast amounts of natural gas and solar energy. the gas could be utilized in compliance with Federal Aviation Authority Emission guidelines for reduction gas emission, which could also alter the ozone layers and promotion of solar powering system for powering and fueling of the UAVs in the country.

The Joint Task Force, Nigerian Navy, Nigerian Security and Civil Defense Corp, and other security agencies operating in this region should be trained, retrained, and equipped with UAVs technology along with proper budgetary allocations for procurement, training, and intelligence operations by the Federal Government in order to combat illegal bunkering. The Nigerian Government, through technological and financial aid, can collaborate with the Nigerian Air Force, Navy, and other security agencies for the socioeconomic development of the Niger Delta and the nation at large, in order to ensure peaceful co-existence. Finally, there is a critical need to automate aerial monitoring with UAVs for intelligent monitoring (i.e., disaster occurrence, security and military operations) and scientific information purposes with proper pre-programmed security and communication systems to combat hacking by insurgents. 


\section{Acknowledgements}

We would like to thank Editage (www.editage.co.kr) for English language editing.

\section{Declaration of Conflicting Interests}

The author(s) declared no potential conflicts of interest with respect to the research, authorship, and/or publication of this article. 
The utilization of unmanned aerial vehicles in... / Dada Kayode Sunday, John • Jechoniah, Akila 121

\section{Reference}

Abdullah, Q.A. (2020). Classification of Unmannered Aerial System: Course Module of Geospatial Applications of Unmannered Aerial System. Pennsylvania State University, USA. Retrieved from www.e-education.psu.edu/geog892/node/5.

Adedoyin, A. (2016). Pipeline Vandalism: Implications On Economy. Retrieved from http://www.economicconfidential.com/2016/05/pipeline-vandalism-implications-economy/

Adishi, E., \& Hunga, M.O. (2017). Oil Theft, Illegal Bunkering and Pipeline Vandalism: It's Impact on Nigeria Economy, 2015 - 2016. International Journal of Economics and Business Management. 3(2), 47-65. http://large.stanford.edu/courses/2020/ph240/bolodeoku2/ docs/adishi-2017.pdf

AeroVironment. (2021). Look, up in the sky *.it's a bird $\cdots$ it's a plane $\cdots$ it's a nano hummingbird. Retrieved from http://www.avinc.com/resources.case--studies/view/look-up-in-the-skyitsa-birdits-a-plane-its-anano-hummingbird.

Ahmed, A., Nagai, M., Tianen, C., \& Shibasaki, R. (2008). UAV based monitoring system and object detection technique development for a disaster area. International Archives of Photogrammetry, Remote Sensing and Spatial Information Sciences. 37, 373-378. https://www.researchgate.net/publication/228336621

Amazon. (2014). DJI Phantom 2 Vision Quadcopter with Integrated FPV Camcorder. Retrieved from http://www.amazon.com/DJI-Phantom-Quadcopter - Integrated-Camcorder/dp/ B00FW78710.

Ambrosia, V. G., Wegener, S., Zajkowski, T., Sullivan, D. V., Buechel, S., Enomoto, F., Hinkley, E.A., Lobitz, B., \& Schoenung, S. (2011). The Ikhana UAS western states fire imaging missions: From concept to reality (2006-2010). Geocarto International. 26, 85-101. https://doi.org/10.1080/10106049.2010.539302

Armada International. (2009). Complete guide drones 2009. Zurich: Armada International.

Asuni, B. J. (2009). Blood Oil in the Niger Delta Special Report. Washington; United States Institute of Peace.

Austin, R. (2011). Unmanned aircraft systems: UAVS design, development and deployment. New York: John Wiley \& Sons.

Bodo, T., \& Gimah, B. G (2019). Oil Crisis in the Niger Delta Region of Nigeria: Genesis and Extent. European Scientific Journal, 15(36), 141-158. https://core.ac.uk/download/pdf/ 
328026866.pdf

Bodo, T., \& Gimah, B. G (2020). The Pollution and Destruction of the Niger Delta. Ecosystem in Nigeria: Who is to be blamed? European Scientific Journal, 16(5), 161-182. https:// doi.org/10.19044/esj.2020.v16n5p161

Bodo, T., Gimah, B. G., \& Seomoni, K. J. (2020). Illegal Oil Bunkering in the Niger Delta Region of Nigeria: A Challenge to Nigeria's Development. European Scientific Journal ESJ, 16(29), 134-154. https://doi.org/10.19044/esj.2020.v16n29p134

Boris, O. H. (2015). Upsurge of oil theft and illegal bunkering in the Niger Delta region of Nigeria: is there a way out? Mediterranean Journal of Social Sciences, 6(3), 563-573. https://doi.org/ 10.5901/mjss.2015.v6n3s2p563

Bowman, R. (2004). Large Unmanned Vehicles. Shephard Unmanned Vehicles Journal, 9, 55-56.

Cai, G., Jorge, D., \& Lakmal, S. (2014). A survey of small-scale unmanned aerial vehicles: Recent advances and future development trends. Unmanned Systems, 2(2), 175-199.

Cai, G., Dias, J., \& Seneviratne, L. (2014). A Survey of Small-Scale Unmanned Aerial Vehicles: Recent Advances and Future Development Trends. Unmanned Systems, 02(02), 175-199. https://doi.org/10.1142/s2301385014300017

Campell, J. (2015). A Primer on Nigeria's Oil Bunkering. Council on Foreign Relations. https://www.cfr.org/blog/primer-nigerias-oilbunkering (Retrieved 10th December, 2019)

Christiansen, R.S. (2004). Design of an Autopilot for Small Unmanned Aerial Vehicles (Master's Thesis). Brigham Young University, pp. 2-4.

Crouch, C. C. (2005). Operations level: implications of operations, implementation, and information sharing. Project, Naval Postgraduate School for Master of Science in Systems Technology.

Cummings, M. L., da Silva, F. B., \& Scott, S. D. (2007). Design methodology for unmanned aerial vehicle $(U A V)$ team coordination. MIT Humans and Automation Laboratory. https://dspace.mit.edu/bitstream/handle/1721.1/46732/HAL2007_05.pdf

Davis, C. L. (2010). The systems integration of autonomous Behavior analysis to create a "maritime Smart environment for the enhancement of Maritime domain awareness." (Master's Thesis). Naval Postgraduate School, Monterey, USA.

Davis, S., Von Kemedi, D., \& Drennan, M. (2006). Illegal Oil Bunkering in the Niger Delta. Unpublished Niger Delta Peace and Security Working Group background paper, June 2006, 40.

Edwards, V. (2009). Stealth hornets: Unmanned aerial vehicle and unmanned combat aerial vehicle UAV/ACAV version of a revolution in military affairs. Conference of Defence 
The utilization of unmanned aerial vehicles in... / Dada Kayode Sunday, John • Jechoniah, Akila 123

Associations. April. http://www.cda-cdai.ca/cdai/ uploads/cdai/ 2009/04/edwards03.pdf (accessed 15 September 2009).

Fahlstrom, P., \& Gleason, T. J. (2012). Introduction to UAV Systems. New York: John Wiley \& Sons.

Federal Aviation Administration. (2007). Unmanned Aircraft Operations in the National Airspace. Federal Register. Accessed April 14, 2014. http://www.gpo.gov/fdsys/granule/FR2007-02-13/E7-2402.

Holland, G. J., Webster, P. J., Curry, J. A., Tyrell, G., Gauntlett, D., Brett, G., ... \& Vaglienti, W. (2001). The Aerosonde robotic aircraft: A new paradigm for environmental observations. Bulletin of the American Meteorological Society, 82(5), 889-902. https://doi.org/10.1175/ 1520-0477(2001)082<0889:taraan>2.3.co;2

Hope for Niger Delta Campaign. (2013). Take a getaway under the Tuscan sun. http://www.nigerdeltacampaign.com/index.php/2009/10/take-a-getaway-under-the-tusca n-sun/

Hugenholtz, C. H., Moorman, B. J., Riddell, K., \& Whitehead, K. (2012). Small unmanned aircraft systems for remote sensing and Earth science research. Eos. Transactions of the American Geophysical Union, 93(25), 236.

Idachaba, F. E. (2013). SPDC- Pipeline Association of Nigeria Conference Port Harcourt-Nigeria. https://www.covenantuniversity.edu.ng/Profiles/Idachaba-Francis/Design-of-an-Autono mous-Pipeline-Surface-Inspection-Robot-for-Offshore-Pipeline-Monitoring

Jaysen, A., \& Yochim, J. A. (1998). The vulnerabilities of unmanned aircraft system common data links to electronic attack. (Master's Thesis). Military Art and Science General Studies, USA.

Jensen, J. R. (2007). Remote Sensing of the Environment: An Earth Resource Perspective. Upper Saddle River, New Jersey: Prentice- Hall.

Katsouris, C., \& Sayne, A. (2013). Nigeri's Criminal Crude: International Options to Combat the Export of Stolen Oil. London: Chatham House.

Kemedi, D. (2006). Fuelling the violence: Non-state armed actors (militia, cults and gangs) in the Niger Delta. Niger Delta Economies of Violence Working Papers No. 10. Berkeley: University of California. http://geography.berkeley.edu/ProjectsResources/ND\%20Website/ NigerDelta/WP/10-VonKemedi. pdf (accessed 3 May 2008).

Klemas, V. V. (2009). The Role of Remote Sensing in Predicting and Determining Coastal Storm Impacts. Journal of Coastal Research, 256, 1264 - 1275. https://doi.org/10.2112/08-1146.1

Klemas, V. V. (2010). Tracking oil slicks and predicting their trajectories using remote sensors 
and models: Case studies of the Sea Princess and Deepwater Horizon oil spills. Journal of Coastal Research, 26(5), 789 - 797. https://doi.org/10.2112.10a-00012.1

Klemas, V. V. (2011). Remote sensing of wetlands: Case studies comparing practical techniques. Journal of Coastal Research, 27(3), 418-427. https://doi.org/10.2112/jcoastres-d-1000174.1

Klemas, V. V. (2015). Coastal and environmental remote sensing from unmanned aerial vehicles: An overview. Journal of Coastal Research, 31(5), 1260-1267. https://doi.org/10.2112/ jcoastres-d-15-00005.1

Kody, F., \& Bramesfeld, G. (2012). Small UAV Design Using an Integrated Design Tool. International Journal of Micro Air Vehicles. 4(2), 151-163. https://doi.org/10.1260/ 1756-8293.4.2.151

Lechner, A. M., Fletcher, A., Johansen, K., \& Erskine, P. (2012). Characterizing upland swamps using object-based classification methods and hyper-spatial resolution imagery derived from an unmanned aerial vehicle. Proceedings of the XXII ISPRS Congress Annals of the Photogrammetry, Remote Sensing and Spatial Information Sciences, 4, 101-106.

NOAA (National Oceanic and Atmospheric Administration), 2008. Hurricane Katrina. Retrieved from http://www.ncdc.noaa.gov/oa/research/2005/katrina.html.

Olive-Drab. (2009). RQ-7 Shadow UAV. Retrieved from www.olive-drab.com/idphoto/id_ photos_uav_rq7.php

Pike, D. (2014). Ocean Eye oil spill aerial tracking. Maritime Journal. Retrieved from http://www.maritimejournal.com/news101/pollution-control/ocean-eye-oil-spill-aerial-tra cking.

Procerus Technologies. (2006). Kestrel User Guide Kestrel Autopilot (firmware version MA8) \& Virtual Cockpit 2.3, Version 1.51. Retrieved from www.procerusuav.com.

Ramesh, P.S., \& Jeyan, M. L. (2020). Mini Unmanned Aerial Systems (UAV) - A Review of the Parameters for Classification of a Mini UAV. International Journal of Aviation, Aeronautics, and Aerospace, 7(3), 1-21. https://doi.org/10.15394/ijaaa.2020.1503

The US National Aeronautics and Space Administration (2009). The NASA/NOAA Global Hawk HALE UAS. Retrieved from www.nasa.gov.

Thomas, B. (2006). Unmanned aircraft systems (UAS) training. Fort Rucker: US Army Aviation Warfighting Center.

US Joint Forces Command (2009b). Drone. A land, sea, or air vehicle that is remotely or automatically controlled. US Military Publications.

US Office of the Secretary of Defense. (2013). Roadmap, unmanned systems integrated roadmap 
The utilization of unmanned aerial vehicles in... / Dada Kayode Sunday, John • Jechoniah, Akila 125

2013-2038.

Watts, A.C., Ambrosia, V. G., \& Hinkley, E. A. (2012). Unmanned Aircraft Systems in Remote Sensing and Scientific Research: Classification and Considerations of Use. Remote Sensing,4(6), 1671-1692. https://doi.org/10.3390/rs4061671

Wikipedia. (2014). Quadcopter. Retrieved from http://en.wikipedia.org/wiki/.

Wifa, B. M. (2008). Developing a model legal and justice sector in the Niger Delta: Prospects and challenges. In Paper delivered at the Niger Delta Development Commission, Nigerian Bar Association Conference on law, peace and Development in the Niger Delta region at Hotel Presidential, Port-harcourt.

Woolpert. (2021). Unmanned Aircraft Systems. Retrieved from www.woolpert.com/services. 
